\title{
Os primeiros cultores da maneira italiana em Portugal
}

\author{
Marcia Arruda Franco \\ (Universidade de São Paulo)
}

\section{RESUMO}

O presente artigo pretende examinar a relação entre poesia, sociedade e poder no século XVI, enfocando o patronato e a introdução do código poético italiano na poesia portuguesa, por meio dos sonetos dedicados ao príncipe Dom João por Sá de Miranda e do diálogo poético entre este e Dom Manuel de Portugal, os primeiros cultores da maneira italiana em Portugal.

PALAVRAS-CHAVE: Sociedade, Código poético italiano, Sá e Miranda, D. Manuel de Portugal.

\section{ABSTRACT}

The present paper means to exam the relationship between poetry, society and power in the 16th century, focusing on the figure of a noble patron and on the introduction of Italian poetry in Portugal, examining the sonnets written to the prince D. João, by Sá de Miranda, and the poetic dialogue between him and Dom Manuel of Portugal, who first used the Italian poetry in Portugal.

KEYWORDS: Society, Italian Poetry, Sá de Miranda, D. Manuel de Portugal. 
Je sais que vous gardez une place au Poëte

Dans les rangs bienheureux des saintes Légions,

Et que vous l'invitez à l'éternelle fête

Des Trônes, des Vertus, des Dominations.

Charles Baudelaire, Bénédiction

O objetivo deste texto é pensar a função social do poeta no século XVI, isto é, a sua utilidade para a sociedade, ou a valorização social da prática poética, a sua afirmação como coadjuvante das formas de poder no período renascentista, por meio da instituição do patronato. Neste momento se julgava que a tipografia e o livro poderiam imortalizar a poesia, livrando-a da corrupção material a que estavam sujeitos os manuscritos, e fazendo dela a fiel depositária da memória, pela preservação dos textos por sua reduplicação ou cópia. Isto não significa de maneira nenhuma que a nova poesia fosse apenas letrada e lida em voz baixa na solidão de uma subjetividade. A palavra mesmo escrita durante todo o século XVI é proferida em presença de um público como meio eficaz de comunicação social. Pela palavra vocalizada em determinada situação concreta do cotidiano, como ato de fala cívico, político e pedagógico, pelo elogio ou pelo vitupério, a poesia é um bem simbólico capaz de civilizar, morigerar e doutrinar o seu público. $\mathrm{Na}$ sociedade quinhentista de corte, impresso ou manuscrito, o poema circula de forma oral, cantado ou pela leitura em voz alta. Como canto ou declamação, se dirige a um público ou ouvinte em presença. O canto épico de Camões, ainda que lamente "cantar a gente surda e endurecida", é dedicado ao rei, e se ficciona como lido em presença de Dom Sebastião, invocado na dedicatória e na conclusão de Os Lusiadas. Como ato cívico e político, o "engenho ardente" do Poeta produz "de tuba canora e belicosa" um "som alto e sublimado" num estilo "grandíloquo e corrente", com o qual pretende enfurecer e mover à guerra de cruzada os cavaleiros do rei, cujos peitos, a escuta do discurso épico "acende e a cor ao gesto muda". A composição poética é movente e circula ao sabor das modulações e nuances das vozes que a recitavam, em performance, nas diversas circunstâncias do cotidiano da corte, nos salões, nas praças públicas, em estalagens, em datas comemorativas, nas variadas cerimônias do Estado monárquico etc., sempre como um meio de comunicação social, cuja função última é zelar pelo pacto de sujeição ao monarca e pela prática dos valores religiosos.

Quando Sá de Miranda reúne as suas poesias a pedido do príncipe Dom João, o malogrado pai de Dom Sebastião, as encabeça cada uma com um soneto dedicado ao príncipe e que alude às relações de reciprocidade entre monarcas e poetas na constituição do poder monárquico. O elogio feito pelos poetas transforma reis em quase deuses, ou seja, o apoio aos poetas pelos príncipes é pago com a imortalidade propagada pela repetição (sempre em diferença) da palavra poética ouvida e reproduzida pela memória, pela cópia de mão, pelos prelos [Ver apêndice]. O príncipe leria os poemas do bom Sá no serão de sua culta corte para deleite e instrução de seus súditos. O poeta crê que a sua poesia, dispersa em folhas manuscritas encomendadas às traças, poderia ser salva do esquecimento e da ruína pelo mecenato do príncipe e da princesa Dona Joana, sua esposa por tão pouco tempo. A prematura morte do herdeiro da coroa portuguesa põe um término à pretensão mirandina de ver as suas poesias à maneira italiana em letra redonda. As suas comédias viram os prelos logo após a sua 
morte e, em vida, a poesia no metro e nas formas peninsulares, em recolhas coletivas, tais como o Cancioneiro Geral de Garcia de Resende; a nova poesia só será impressa em 1580, quando o soneto a respeito do afortunado tema de Leandro e Hero for publicado nos comentários de Herrera a Garcilaso de la Vega, cujo livro manuscrito Sá de Miranda ganhara de seu amigo António Pereira Marramaque, antes de 1536, e quando for reunida em 1595, na tipografia de Manuel de Lira.

A vocação cívica e educacional da poesia se intensifica no renascimento e no humanismo, quando à palavra é dado o valor de identificar os humanos entre os deuses e os animais, segundo a célebre oração de Pico Mirandolano. No Renascimento, o poeta é consciente e preza a sua racionalidade, ao se reconhecer um espaço subjetivo e pensante, cujo engenho produz a arte das palavras. Mesmo sujeito ao pacto monárquico, teoricamente, o sujeito cristão goza a opção da escolha, o livre-arbítrio que o dirige nos caminhos certos ou errados da vida. Nesta tarefa de ensinar a reflexão moral e a conduta ética e decorosa é que o estudo das letras, da religião e da filosofia é útil como instituição do império lusíada e do Estado monárquico. Com o advento da tipografia, o papel cívico e de utilidade social da poesia se viabiliza sem substituir e sim de forma suplementar à transmissão do livro manuscrito. Tal situação híbrida de convívio entre o impresso e o manuscrito permanecerá durante alguns séculos. No século XVI, a nova poesia italiana e renascentista trazia em seu bojo o estudo, a leitura e a criação de um espaço de experiencialismo métrico-formal para o poeta e se beneficiava mais dos meios manuscritos, pois só conheceu o novo meio de transmissão impresso nas décadas de 1580 e1590.

O novo princípio criativo, a imitação dos modelos da tradição italiana e antiga, pautado na busca da forma mais bem acabada, fundava-se na incessante reescrita do texto, no curso da qual a opinião de outros poetas poderia interceder, não apenas pela cópia, mas pela emenda efetiva do texto do aprendiz de poeta novo. Tal processo se dava pela circulação manuscrita, sendo os poetas responsáveis por recolhas de sua própria poesia, cópias manuscritas feitas para oferta a outro poeta-mestre, com o fim de obter uma avaliação crítica acerca da composição ou poema novo. Desta forma, os poetas estão seguindo um preceito horaciano elementar, o de nunca publicarem nada que não tenha sido relido por um terceiro. Entretanto, dada a indústria complexa e em certa medida eficiente do livro de mão para a circulação do poético, tais cópias eram de fato publicações da obra. António Ferreira alerta os seus colegas a respeito de apenas lerem em voz alta a um amigo, e não deixarem manuscrito de sua poesia, pois a palavra uma vez ida, por meio da escrita, não poderia mais tornar ao que a escreveu e ser limada, sendo não só preservada como inscrição pela releitura, mas também desapropriada pela reprodução.

No terceiro soneto dedicado ao príncipe, e que encabeça a última recolha enviada de suas poesias, consciente deste complexo sistema de circulação da palavra poética, Sá de Miranda verifica não poder seguir Horácio mais do que em aparência. Malgrado Ferreira, nesta troca manuscrita (posteriormente impressa) entre os novos poetas em busca de mútuas correções diante do processo de aquisição do novo código poético é que se pode surpreender o processo de instituição do sistema poético moderno em Portugal e na língua portuguesa. Deste modo se justifica o estudo e a reedição da correspondência poética entre Sá de Miranda e dois poetas contemporâneos, Dom Manuel de Portugal e Pêro de Andrade Caminha, e dos textos dedicados a figuras eminentes da vida pública, como espécies de documentos da história da poesia moderna portuguesa no século XVI. Nestes diálogos e dedicatórias em torno do código renascentista são desenhados os 
pressupostos e as concepções poéticas novas, sendo feita uma reflexão a respeito do lugar e da função ou valor social da nova poesia.

Ao lado de reuniões de poemas feitos para oferta a figuras públicas ou potenciais mecenas, como no caso aqui editado dos três sonetos ao príncipe Dom João, os poetas entre si travavam um pequeno comércio, em que a moeda era a própria escrita, o pagamento feito com capital literário. As correspondências, epístolas e pequenas recolhas de poesia, muitas vezes, eram textos cujo propósito era agradecer e retribuir a gentileza intelectual de amigos letrados, como no caso de Encantamento, a écloga mirandina dedicada a Dom Manuel de Portugal. Ou no caso de Nemoroso, écloga escrita para chorar a morte de Garcilaso, mas também para pagar aos letrados Pereiras, de Cabeceira de Bastos, o presente recebido: o livro manuscrito do lírico espanhol.

Pensamos que examinar o diálogo travado entre os poetas portugueses quinhentistas no momento em que as novas formas italianas começam a ser cultivadas em Portugal lança alguma luz a respeito da revalorização social do fazer poético quinhentista com ênfase na busca do ritmo italiano e da nova concepção do poético pautada no estudo dos antigos e na reflexão sobre o presente do século XVI.

O texto das dedicatórias de poemas, as epístolas e correspondências, o diálogo em torno da nova poesia travado entre poetas parecem ser lugares onde se mostra a redefinição do papel social do poeta e da poesia quinhentistas. Ainda fortemente dependente da transmissão oral, congenial à prática poética nas monarquias católicas, a produção do texto poético cada vez mais exige do poeta o conhecimento de textos antigos e italianos, com a série de referências retóricas e mitológicas prescritas pela Imitatio e pelo decoro, ou adequação da matéria ao gênero discursivo e à situação social de proferimento. Através da intensa epistolografia trocada entre os poetas da escola nova e as figuras públicas da vida quinhentista é possível acompanhar a institucionalização cívica e pedagógica da palavra poética nova na sociedade de corte portuguesa durante o século XVI.

Os estudos literários que se movem para a retirada da responsabilidade de Sá de Miranda pela introdução do novo código poético, de certa forma, correm movidos pela saudável intenção de mapeamento do sistema poético português quinhentista, isto é, do conjunto de produtores e receptores do poético, cuja nova função social, cada vez mais cívica, se organizou em torno do novo conceito do poético. Tal tendência, a intenção de aliviar dos ombros do poeta do Neiva a gesta poética de introdução da nova poesia em Portugal, está no estudo introdutório do editor da Poesia de D. Manoel de Portugal (FARDILHA, 1991). Assim expressa o jovem editor o seu louvável propósito: "No nosso ponto de vista um ponto de vista formulado a partir dos textos, à falta de outros documentos mais 'objectivos' -, há, assim, que repensar a posição de D. Manoel de Portugal como discípulo mirandino e, até, a responsabilidade única e inquestionável de Sá de Miranda na introdução das novas formas em Portugal" (FARDILHA, 1991 p. XXXII).

Do nosso ponto de vista, uma vez que concordamos com o fato de a reforma poética ter sido uma empresa coletiva de Sá de Miranda e seus contemporâneos, importa explicitar qual a centralidade de fato gozada por Sá de Miranda no panorama poético do século XVI, quando está em processo a renovação da tradição trovadoresca pela nova poesia, e ainda mostrar em que medida Dom Manuel de Portugal permanece um discípulo mirandino.

Fardilha defende a posição de que as pesquisas de D. Manuel (considerado por Carolina Michaelis de Vasconcelos o primeiro imitador de Sá de Miranda) em 
torno do novo ritmo foram simultâneas às do poeta no seu retiro da corte sendo, portanto, incorreto falar em precedência ou em magistério mirandinos.

Ao argumento de Fardilha, interessa acrescentar que as pesquisas com o novo código poético nos poetas quinhentistas da escola mirandina, ou da escola nova, foram não só simultâneas, mas também discutidas, como se pode ler nos sonetos, nas cartas e dedicatórias que trocaram entre si, textos impressos nas edições príncipe de 1595, e, com variantes, na segunda, de 1614, das obras poéticas de Sá de Miranda. As correspondências, os diálogos e dedicatórias poéticas tematizam a própria reforma poética urdida por Miranda e seus contemporâneos. Aí, Sá de Miranda ocupa um lugar central na difusão do novo código poético, sobretudo, por sua ciência de humanista cristão, capaz de lançar mão dos exemplos da sabedoria cristã e também da pagã, a fim de ensinar uma visão do mundo crítica e racional, e ainda cristã e fortemente moralizadora.

A leitura que Fardilha faz dos sonetos trocados entre D. Manuel e Sá de Miranda é, porém, discutível. Para começar, a sua argumentação de que D. Manuel não é um discípulo mirandino e sim um poeta que experimentou o ritmo italiano na mesma época de Sá de Miranda, parece se apoiar em um erro de transcrição textual. O editor ao transcrever (da edição de 1595 das obras mirandinas) o soneto de D. Manuel "Soem às vezes ser mais estimadas" (enviado por volta de 1535 a Sá de Miranda, junto com a écloga "Dexando los ganados rumiando") comete um erro estratégico. O verso "Por isso ante vós vão confiadas" (MIRANDA, 1595, p. 6) é transcrito, tanto no texto introdutório como no corpo do livro (FARDILHA, 1991, pp. XXIX e 118), como "Por isso ante vós não confiadas" (grifo meu). Deste modo, o editor de D. Manuel de Portugal pode considerar que há entre este poeta e Sá de Miranda apenas uma relação de "estima e amizade" e não uma relação de "dependência literária".

A crítica de Fardilha não se justifica, não só porque parte de um erro, justamente no verso em que D. Manuel confia a Sá de Miranda a leitura de "Dexando los ganados rumiando", mas porque Sá de Miranda sempre recusou o lugar de mestre da nova medida, consciente da sua dificuldade como versejador do novo ritmo, por não ser esta a área do seu magistério. Na resposta a D. Manuel, o poeta é bem claro em relação aos seus limites de versejador, colocando-se abaixo do representante da Casa de Vimioso. O problema pode ser posto mais objetivamente. Como já observou, no século XVII, Faria e Sousa, célebre editor de Camões, D. Manuel é melhor versejador da nova medida do que Sá de Miranda. O comentador das Rimas varias considera que

Parecieronse los dós en Portugal a Boscán y a Garcilaso en Castilla: porque si Boscán los resucitó, fue con gran escabrosidad; y Garcilaso lo prosiguió con numero suave. De que acertase más en esto D. Manoel que Francisco de Sá, me admiro yo; porque este anduvo por Italia, adonde esto se ejercitó siempre mejor; y esotro no sé que saliese de Portugal (apud FARDILHA 1991, p. XXVIII, n. 56).

Faria e Sousa ao comparar D. Manuel e Garcilaso tem em mente apenas o domínio do ritmo toscano. Para quem lê a Prophana de D. Manuel de Portugal é muito interessante perceber a busca e a conquista do ritmo peregrino nos textos em português, confrontando-as com a dificuldade mirandina. E é sempre motivo 
de proveito perceber a grande ciência mirandina, não só em suas composições ásperas e duras, mas também nos conselhos oferecidos em suas respostas a D. Manuel de Portugal e a outros que o procuraram, como Pêro de Andrade Caminha, ou a quem se dirigiu.

Sá de Miranda, como dissemos, recebeu com entusiasmo e camaradagem as experiências felizes de outros quinhentistas com o novo metro. Na dedicatória de Encantamento [VV. 1-40], admite que o fato de D. Manuel também estar empenhado na empresa da reforma poética, e em cantar uma nova concepção do amor, causava-lhe surpresa e encantamento, levando-o a repensar a posição dos portugueses diante da nova medida e do novo gosto italiano. O poeta considera legítima (e até melhor que a sua) a pesquisa de D. Manuel com o novo gênero e o novo metro, surpreso por alguém em Portugal tentar, como ele, no seu "escondedouro", a nova medida no discurso pastoril

Então tornando em mim, disse comigo,

Certamente eu trazia errada a conta,

Que inda há quem nos renove o tempo antigo

De que tanto se escreve, e tanto conta.

Agora me reprendo, e me castigo,

Fazia à nossa Lusitânia afronta,

Cuidei que só buscava prata e ouro,

Buscastes-me no meu escondedouro. [VV. 17-24]:

Pronto a refazer as suas contas, Sá de Miranda está feliz por ter encontrado um português interessado na busca do novo código poético, de "prata e ouro". Vendo a iniciativa de D. Manuel em cultivar o novo metro, novas formas e novas rimas, o poeta repreende-se de julgar que os portugueses, ao contrário dos castelhanos, não se interessavam pela introdução dos cantares peregrinos, elogiando o canto do amor feliz neste representante da Casa de Vimioso [VV. 1$15]$.

Alexandre M. Garcia (1984) considera que a referência de Miranda aos seus limites de versejador, expressa na última estrofe da dedicatória a D. Manuel [VV. 33-40], não deve ser vista como um "simples topos retórico de modéstia literária" (MIRANDA, 1984, p. 259). Sá de Miranda "parece demonstrar uma consciência muito viva de que nem sempre a perfeição que torturadamente se busca é alcançada"(Idem, Ibidem). Miranda se comporta na dedicatória de Encantamento da mesma forma que D. Manuel no soneto-dedicatório que antecede "Dexando los ganados rumiando", ambos pedem compreensão para as suas dificuldades. Por isso o poeta diz, medindo os seus passos: "fiz o que pude".

Querem-vos por senhor, não por juiz,

Rigores a de parte, que são dignos

De perdão os começos: já que fiz

Aberta aos bons cantares peregrinos,

Fiz o que pude, como por si diz

Aquele um só dos líricos latinos, ${ }^{1}$

Provemos esta nossa linguagem,

E, ao dar da vela ao vento: - Boa viagem!

O fato de D. Manuel ser melhor versejador da medida nova quer dizer que tinha melhor ouvido para ela do que Sá de Miranda; não quer dizer, porém, que 
tenha começado a experimentar com a nova medida antes de ter lido alguma écloga mirandina escrita em espanhol e que tratasse da questão da nova poesia. Ao tentar o soneto, o novo metro e o novo ritmo em éclogas luso-castelhanas, o poeta foi além da escola bernardiniana, peninsular ou cancioneiril, passando a ser o catalisador do novo código poético, na primeira metade do século XVI. A correspondência com D. Manuel se deu depois de "Alexo" e da "Fábula do Mondego", escritos nos anos 1520, e antes de "Nemoroso", de 1537, poemas bucólicos que Sá de Miranda escreveu em castelhano e na nova medida, além de outros como "Célia", "Andrés" e "Epitalâmio Pastoril".

Sá de Miranda recusava a posição de mestre da nova medida, mas não abria mão do seu papel de introdutor dos cantares peregrinos em Portugal e na língua portuguesa. Quando D. Manuel confia a sua écloga luso-castelhana a Miranda, este "paga" a cortesia com a primeira écloga na nova medida e em língua portuguesa: Encantamento. Para o editor da Prophana, começos referem-se aos versos enviados em resposta a D. Manuel, que já teria escrito "ao menos uma écloga", antecedendose a Miranda. É importante assinalar que a écloga enviada a Sá de Miranda por D. Manuel, "Dexando los ganados rumiando", é uma obra luso-castelhana, isto é, escrita em língua espanhola, como tantas outras de Miranda, pois Encantamento não foi a primeira obra de Sá de Miranda nem na medida nem no espírito da poesia pastoril, mas foi a primeira escrita em português e na nova medida.

Miranda quer D. Manuel por senhor, não por juiz, dos versos de Encantamento. Este assenhoramento deve deixar "os rigores a de parte", perdoando versos que estavam nos começos da aventura de captação do novo ritmo, em português. D. Manuel deve assenhorar-se da atitude mirandina e escrever melhores decassílabos portugueses, depois que Sá de Miranda abriu o mar da poesia portuguesa ao novo metro, outro poderia prosseguir a viagem prosódica em busca do ritmo italiano em língua portuguesa, com votos de felicidade.

Na Prophana de D. Manuel de Portugal não há nenhuma composição de vulto em português. Os começos referem-se então às primeiras tentativas mirandinas com a nova medida, na língua materna. Doutro modo a estrofe final da dedicatória de Encantamento [VV. 35-40] fica sem sentido, não se entende a comparação feita entre o próprio Sá de Miranda e Horácio, que, ao introduzirem um novo metro, "fizeram o que puderam", e muito menos a comparação entre a gesta do poeta e a dos descobridores portugueses.

É certo considerar que a geração de D. Manuel dinamizou as experiências com o decassílabo na corte de D. João III, paralelamente às experiências mirandinas, no seu retiro das Duas Igrejas. Isto não impede a avaliação do tipo de centralidade gozada pela poética mirandina no processo de introdução do novo código poético entre os líricos portugueses, até porque construída topicamente por Ferreira e pelos contemporâneos, de modo a permanecer como modelo de virtude para os escritores do século XVII. Até meados do século XVI, quando morreu, a Sá de Miranda foram confiadas obras de quase todos os quinhentistas que tentaram a medida nova e o novo processo criativo, a Imitatio. Todo o processo de introdução do novo código foi amplamente discutido entre os poetas pela prática intensa da epistolografia em verso e Miranda é sempre o exemplo da nova poesia. Os poetas da escola nova o procuravam como praticantes mais bem sucedidos do novo metro, mas almejavam a sua ciência, isto é, o seu conselho filosófico-humanista.

É positivo o esforço do editor em "socializar" a busca do ritmo italiano e a empresa da reforma poética. Mas o que faz de Sá de Miranda uma figura basilar do Renascimento português é a sua ciência de humanista cristão, em que não raro aflora uma nota supersticiosa, característica da mentalidade quinhentista. É no 
sentido de socialização e coletivismo que importa repensar a simultaneidade dos experimentos com o ritmo toscano, em português ou em castelhano, entre os líricos portugueses, enfatizando-se o lugar especial do douto Sá de Miranda. Mesmo Jorge de Montemor, o músico poeta que doma o ritmo italiano em língua castelhana, um grande sucesso no século XVI, irá escrever a Sá de Miranda atrás de sua ciência, o fruto maduro e desejado. Os poetas da escola italiana - D. Manuel de Portugal, Pêro de Andrade Caminha, António Ferreira, Diogo Bernardes, André Falcão de Resende, Camões, confiaram suas produções uns aos outros e, menos o último, ao parecer do sábio Sá de Miranda, criando assim uma rede de comunicação poética em português, que punha na ordem do dia a questão da nova medida e do novo conceito de poesia subjacente à prática poética italiana e renascentista.

Também o diálogo de arte-poética travado entre os dois primeiros sonetistas portugueses pode ser examinado, incluindo-se a discussão das pesquisas estéticas na corte de D. João III, e de Sá de Miranda no campo, no período de tempo em que coexistiram historicamente na primeira metade do século XVI. Apesar de ouvirmos como o ritmo do decassílabo italiano é captado pelo soneto de D. Manuel, não se pode negar, na correspondência com Sá de Miranda, certo magistério mirandino: o ensino de outra forma de compor "não natural" fundada na cultura antiga, ou no cultivo da poesia como coisa verbal, cuja finalidade última seria criar um espaço reflexivo, de questionamento do sujeito, da sociedade e da própria poesia. A correspondência dos cultores da escola nova com Sá de Miranda aponta para esta faceta do sistema poético português: a formação de um novo conceito de poesia fundado na leitura, no estudo, no ócio e na amizade (NEIVA, 1999) e na valorização da escrita poética como manifestação do mais alto espírito humanista cristão.

O outro soneto de D. Manuel de Portugal dedicado a Sá de Miranda é o que integra o paratexto da primeira edição das obras mirandinas, em 1595. Vale citar alguns trechos deste soneto escatológico que aludem à tensão, característica da pena mirandina, entre conceito e ritmo. Por exemplo, diz D. Manuel : "Ao som de teu esprito a que cantaste, / Nunca assi respondeu eco sonoro". No segundo quarteto a referência ao canto de Miranda nos céus é irônica: "Indo desta região, donde inda moro / Saudoso de ti, que amando, voaste / A esta luz: magino desque entraste / Que versos cantarás no eterno coro" (FARDILHA, 1991, p. 127).

Nos tercetos, a ironia é abandonada com a referência ao aspecto reflexivo que a voz mirandina acorda. O conceito dos versos de Sá de Miranda sempre suscita a admiração: "Tua voz acordando, e teu conceito,/ Com um e outro esprito, qu'em seu canto / Do que sempre assi vê, sempre se admira". Dom Manuel acaba o soneto referindo-se ao fato de Miranda inspirá-lo a "soar uma culta lira".

Em suma, entre os poetas da corte de D. João III e Sá de Miranda existiu uma relação literária documentada em correspondências e dedicatórias poéticas. Por meio do estudo de tais correspondências poéticas é que se pode surpreender o surgimento do sistema poético novo em português em torno da "culta lira" de Sá de Miranda. Surge uma nova concepção do poético fundada na leitura que o renascimento fez das poéticas e retóricas antigas, aliada às as premissas do humanismo cristão. Direciona-se a prática poética ao bem-comum e conquistase para o poeta um lugar no trono dos poderosos. Os novos poetas são nobres de letras e de armas, como Camões e André Falcão de Resende, são também homens de leis, de cânones, magistrados e eclesiásticos, que se dedicam ao santo ócio da leitura e ao estudo dos antigos, como Sá de Miranda, Dom Luiz, Dom Manuel de 
Portugal, Pêro de Andrade Caminha, Diogo Bernardes, António Ferreira, Frei Agostinho da Cruz, Jorge de Montemor etc

A tese da camaradagem entre os poetas da escola nova é pertinente e se evidencia nos textos desta correspondência poética, presentes em manuscritos, e nas primeiras edições lado a lado; nos sonetos encomiásticos que abrem as primeiras edições quinhentistas ou que são dedicatórias de poemas ou livros. A primeira edição das obras de Sá de Miranda mantém o par de textos em diálogo, imprimindo os sonetos de Dom Manuel e Caminha a Sá de Miranda seguidos das respostas de Sá de Miranda. Do mesmo modo imprimem a correspondência do poeta com Jorge de Montemor e com António Ferreira, e as dedicatórias das éclogas, deixando entrever não apenas o caráter dialógico e espetacular da poesia, mas o complexo processo de institucionalização da nova maneira italiana.

Também trazem informação sobre a ideia de valor social do poético quinhentista as rubricas a cartas, sonetos, elegias etc. Outro conjunto de textos, por exemplo, de cartas cujo tema se refere aos tempos quinhentistas, como a guerra de cruzada, as grandes descobertas, o comércio de especiarias, a crise religiosa etc, nos representaria também a função civilizadora e doutrinária do poético, ou de como a poesia é mais útil à monarquia pelo elogio da religião cristã, dos reis e heróis lusíadas do que pela formação no seu cultor de um ponto de vista crítico e racional. No império lusíada, nas cartas dirigidas aos reis e ministros, os poetas quinhentistas fizeram da sua escrita uma tribuna de defesa dos valores da ética e da moral cristã humanista nas práticas religiosa, mercantilista e política, no Estado da Índia e na Metrópole. Acréscimo do bem comum e da memória das nações, ao elogiar, sob a ótica cristã, os feitos heroicos dos reis e dos povos, a poesia épica e a sátira moral e cívica souberam garantir o seu lugar institucional na sociedade moderna, ao lado de reis e sacerdotes. A história da poesia portuguesa pôde, entretanto, conferir aos escritores do seu século de ouro quinhentista significados menos históricos e mais liberais, ao canonizá-los com o halo santo de primeiros modernos. 


\section{APÊNDICE - TEXTOS DE SÁ DE MIRANDA E CONTEMPORÂNEOS}

\section{[1] Ao príncipe Dom João nosso senhor, quando lhe mandou pedir estas suas obras}

\section{Soneto ao Príncipe nosso senhor}

A Príncipe tamanho, cujo rogo

(E mais òs ${ }^{2}$ seus) inda ${ }^{3}$ é mais que mandar,

Que posso i al ${ }^{4}$ fazer, senão passar

Pela água, pelo ferro, e pelo fogo?

Se me firo, me queimo, se me afogo,

Se dou de mim às gentes que falar,

Levemente se pode desprezar

Tal dano, e inda mal que não foi logo!

Mas era quase tudo encomendado

À traça, e a não sei quê, com tal presteza,

Com que já quase em pó tudo é tornado. ${ }^{5}$

Já agora, grã senhor, tudo despreza

Quem sai à praça por vosso mandado,

Abasta o nome só de vossa Alteza.

\section{[2] À segunda vez que lhe mandou mais papeis}

Inda que em vossa Alteza a menos parte

Em que Deus ajuntou tantas, e tais,

Seja esta, todavia, entre as Reais,

Se contou ela sempre em toda parte:

Dar favor aos engenhos e a toda arte,

Das boas, faz os Reis aqui imortais

Por fama: inda passando avante mais

Uns fez deuses de todo, outros em parte.

À guerra leva o mor Cipião ${ }^{6}$ consigo

As Musas brandas de seu natural,

Que assi sem armas são d' altas ajudas:

Ainda nos cantam do bom tempo antigo.

Caíram as estátuas de metal!

Que al se podia esperar de cousas mudas? 


\section{[3] À terceira vez, mandando-lhe mais obras}

Tardei, e cuido que me julgam mal, Que emendo muito, e que emendando dano. - Senhor, porque hei grã medo ao mau engano Deste amor que nós temos desigual!

Todos a tudo o seu logo acham sal, Eu risco e risco; vou-me de ano em ano: Com um dos seus olhos só vai mais ufano Filipo, assi Sertório, assi Anibál. ${ }^{7}$

Ando c'os ${ }^{8}$ meus papéis em diferenças, São preceitos de Horácio (me dirão), Em al não posso, sigo-o em aparenças:

Quem muito pelejou como irá são? Quantos ledores, tantas as sentenças, C’um vento velas vem, e velas vão

\section{[4] Soneto de Dom Manuel de Portugal, a Francisco de Sá, mandando-lhe ia écloga}

Soem às vezes ser mais estimadas As pálidas espigas puramente

Ofrecidas, que o ouro reluzente, Descoberto por veias soterradas.

Por isso, ante vós vão confiadas (Raríssimo Francisco, e excelente) A rudeza de estilo diferente

$\mathrm{E}$ as incultas estanças desornadas.

O que brotou de si a natureza,

Da arte nem do artifício ajudada, Colhido sem sazão, senhor, ofreço.

A vontade de vós seja estimada, Que em tão baixo tempo, em que pureza, Em que obras não há, deve ter preço. 
[5] Resposta de Francisco de Sá, Pelos mesmos consoantes, como fez o Petrarca

Tantas mercês tão desacostumadas, Como as servirei eu devidamente?

Farei como já fez um inocente, Um rústico pastor dentre as manadas:

Que d'água ofreceu em mãos lavadas A Xerxes': Bebeu ele, e santamente Jurou que não bebera té o presente, Com tal sabor, por copas douro obradas.

Senhor Dom Manuel, se a só clareza Dum peito aberto, puro, e fé lavada Muito merece, muito vos mereço.

A pedraria vãmente estimada, Os ricos cristalinos de Veneza, Lá se acham, eu òs ${ }^{10}$ meus palmos me meço.

\section{[6] Soneto de Pero de Andrade Caminha ${ }^{11}$ que lhe mandou com ia écloga}

Não ousaram atégora aparecer

Estes versos, de si desconfiados, Porque, de mal compostos e ordenados, Assaz têm porque devam de temer.

Vão-vos pedir, senhor, que os queirais ver E riscar e emendar porque emendados Por vós possam andar mais confiados Do que por meus puderam merecer.

Vai i Androgeu triste, e vai Serrano, Queixa-se este presente, aquele ausente, No Mondego, por vós celebrado.

Queixam-se Ninfas dele, aqui do dano, Que por Sílvia ${ }^{12}$ se vê nele - e se sente Triste - dela e de vós, desemparado. 
[7] Resposta de Francisco de Sá, pelos mesmos consoantes, como fez o Petrarca:

Assi que me mandáveis atrever

A versos já das Musas asselados,

E àquela grã Sílvia ${ }^{13}$ consagrados,

Ícaro me põe medo, e Lúcifer! $!^{14}$

Os meus, se nunca acabo de os lamber, Como ussa $\mathrm{a}^{15}$ os filhos mal proporcionados, (Ah! Passatempos vãos! Ah! Vãos cuidados!) A quem posso porém nisso ofender?

Tudo cabe no tempo, entrego ao ano,

Qual anda o furioso assi emendado.

Torno às cousas sagradas, que um profano, Leigo, como eu, tocá-las tão somente

Não é de siso são mas de abalado.

[8] Soneto constante do aparato paratextual da edição de 1595 das obras mirandinas

Alma felice, a nós, alto decoro

De virtude, por quem os Reis deixaste,

Ao som do teu esprito a que cantaste,

Nunca assi respondeu eco sonoro.

Indo desta região, donde inda moro

Saudoso de ti, que amando voaste

A esta de luz, magino, des que entraste,

Que versos cantarás no eterno coro.

Tua voz acordando, e teu conceito, Com um e outro espírito, que em seu canto

Do que sempre assi vê, sempre se admira.

Recebe o que de ti sente este peito, Por devido louvor, e estima, quanto Ora te faz soar ia culta Lira. 


\section{[9] Dedicatória da écloga Encantamento, de Sá de Miranda, a D. Manuel de Portugal}

Filho daquele nobre e valeroso

Conde, mais junto à casa alta Real, Abastara dizer do Vimioso, ${ }^{16}$

Senhor dom Manuel de Portugal:

Lume do paço, das Musas mimoso, Que certo vos darão fama imortal, Quando homem cuida que no cabo estais, Tornando olhos a vós, por vós passais.

Em que vos servirei cá desse monte ha mercê, na terra pouco usada, Tanto em outra aqui logo defronte? Aquela écloga vossa me foi dada, Encostado jazendo à minha fonte, De versos estrangeiros variada, Parecia que andava a colher flores, Com as Musas, com as graças, c'os amores.

Então tornando em mim, disse comigo, Certamente eu trazia errada a conta, Que inda há quem nos renove o tempo antigo,

De que tanto se escreve, e tanto conta, Agora me reprendo, ${ }^{17}$ e me castigo, Fazia à nossa Lusitânia afronta, Cuidei que só buscava prata e ouro, Buscastes-me no meu escondedouro.

Andando após a paga, houve aos sisos ${ }^{18}$ Grã medo (que o confesso) e a uns pontosos, ${ }^{19}$ De rostos carregados, e de uns risos Sardónios, ou, mais claro, maliciosos, Quem tantos tentos, quem tantos avisos Terá, que empare os golpes perigosos, $\mathrm{E}$ acostumados ora entre pastores? Que vos venham cantando os seus amores.

Querem-vos por senhor, não por juiz, Rigores a de parte, que são dignos De perdão os começos: já que fiz Aberta aos bons cantares peregrinos, Fiz o que pude, como por si diz Aquele um só dos líricos latinos, ${ }^{20}$ Provemos esta nossa linguagem, 


\section{NOTAS}

1. Refere-se a Horácio que introduziu em Roma os metros gregos.

2. òs, aos.

3. Inda, ainda

4. I, aí/então; $a l$, outra coisa: que posso $i$ al fazer, que posso então outra coisa fazer.

5. Observe a saudação do poeta ao príncipe, cujo pedido para que lhe copiasse as suas poesias é recebido como a solução para o perecimento material por que passavam os seus manuscritos, entregues às traças. Com o dever da oferta, o poeta passa por um torturado processo de revisão dos seus textos, para que circulassem manuscritos na corte do casal de mecenas, o príncipe Dom João e a princesa D Joana, ao menos esperançoso de que fossem impressos. O soneto introdutório é de praxe nos cancioneiros autorais, quando o poeta reúne a sua poesia e a encabeça com uma reflexão sobre o seu fazer poético.

6. Cipião foi um "general romano, que se distinguiu na $2^{a}$ guerra púnica. Depois da batalha de Canas, recolheu-se a Canossa, e, com a sua eloquência, convenceu as suas tropas a não se entregarem aos cartagineses. Venceu Aníbal na batalha de Zama; motivo por que foi chamado o Africano. Plutarco transcreve a tradição antiga, segundo a qual Cipião se entregou no exílio aos estudo das letras, e que Sá de Miranda referencia neste soneto.

7. Filipo, Sertório e Aníbal, capitães da Antiguidade, eram cegos de um olho. No século XVI Anibál é palavra oxítona.

8. Cos, com os.

9. Xerxes, rei da Pérsia, filho de Dario, segundo CMV “esta alusão reaparece sempre que um poeta pretende humilhar-se aos olhos do Mecenas que a sua poesia glorifica" (1885, p.759).

10. òs, aos.

11. Poeta quinhentista praticante da nova poesia italiana.

12. Musa dos versos de Caminha.

13. Sílvia é a musa de Caminha.

14. Ícaro e Lúcifer ousaram além da medida, por isso sendo punidos com a queda ou precipitação.

15. Ussa, ursa.

16. Vimioso, (Conde de), Dom Manuel de Portugal era de uma das mais nobres famílias do reino e tão ilustre nas letras como nas armas. Além das suas poesias profanas (Ver Fardilha, 1991, p. 199), deixou um volume de Obras Espirituais. No fim da vida fez-se místico e ascético.

17. Reprendo, Repreendo.

18. Aos sisos, às opiniões, juízos, críticas.

19. Pontosos, escrupulosos.

20. Refere-se a Horácio que introduziu em Roma os metros gregos. 


\section{REFERÊNCIAS BIBLIOGRÁFICAS}

ANASTACIO, Vanda, Visões de Glória (uma introdução à poesia de Pêro de Andrade Caminha), Lisboa, FCG-JNICT, 1998, 2 vols.

FARDILHA, Luís Fernando de. Sá. Poesia de D. Manoel de Portugal I Prophana. Edição das suas fontes por -. Porto, Instituto de Cultura Portuguesa, 1991.

FARIA E SOUSA, M. Rimas Várias. Edição fac-similada. Lisboa, INCM, 1972. 2 vols.

NEIVA, Saulo. Au nom du loisir et de l'amitié. Rhétorique et morale dans l'ếpitre en verse en langue portugaise au XVeme siècle. Paris, C.C. Calouste Gulbenkian, 1999.

Poesia de Sá de Miranda. Organização, notas e sugestões para análise literária de Alexandre M. Garcia. Lisboa, Editorial Comunicação, 1984.

Poesias de Francisco de Sá de Miranda. Edição feita sobre cinco manuscritos inéditos e todas as edições impressas, acompanhadas de um estudo sobre o poeta, variantes, notas, glossário e um retrato por Carolina Michaëlis de Vasconcelos, Halle, Max Niemeyer, 1885.

Francisco de Sá de Miranda - Poesia, Edição de Marcia Arruda Franco. Coimbra, Angelus-Novus, 2010 (no prelo). 